\title{
The Development of a Portable Soil Surface Profiler and its Application
}

\author{
Gang Li*, Jin-Juan Zhang, Fang-Chun Lu and Sui-Gao Ye \\ Institute of Soil and Water Conservation, Zhejiang Institute of Hydraulics \& Estuary, Hangzhou, China
}

\begin{abstract}
This paper designed a portable device for measuring the soil surface profile. This measuring device should have the advantages of automation, high precision, high efficiency, low cost, convenient transportation, and wireless transmitting data. It was mainly composed of a body frame (rail trestle), a motor-trolley, and data system. The motor-trolley can walk along the crossbeam of the body frame. When motortrolley walking, the laser range finder installed on motor-trolley will measuring the points of the soil surface profile. While, the measuring data will be transmitted to receiving laptop. Through soil surface profile two-dimensional data achieving, and the integration of multiple soil surface profile data, the three-dimensional data of the slope can be got. Using common data analysis software will be able to reconstruct the soil surface microrelief.
\end{abstract}

\section{Introduction}

Slope is the most basic geomorphic of soil erosion. In water erosion area, the slope rill and gully formed by erosion are the basic microrelief characteristics, which also are called soil surface roughness [1]. These large and small gullies reflected the soil erosion intensity. According to the sediment data from global 56 different regions, the maximum sediment yield of gully erosion accounted for $94 \%$ of the total sediment yield [2]. Obviously, gully erosion plays an important role in soil erosion. Therefore, how to measure and quantify the microrelief is the pivotal factor of influencing the development of soil erosion science. With the development of measuring microrelief, scholars have proposed many methods and quantitative indicators in the research of soil erosion [3]. Measuring methods can be divided into two categories: the contact and the noncontact. In the early stage, the contact measuring methods were mainly the chain method [4], rod-ruler method [5], pin method [6] and real-time kinematic method [7]. Modern non-contact measuring methods included ultrasonic ranging method [8], infrared sensors method [9], laser range method [10], 3D laser scanner method [11] and close range photogrammetry method [12].

Accurate measurement and quantification of soil surface roughness have important significance to the establishment of soil erosion process model. In view of measuring efficiency, precision, cost and the advantage of laser technique, this paper designs a portable soil surface profiler based on two-dimensional data acquisition. The device has characteristics of rapidly measuring, high precision, low cost and simple data posttreatment. It is a reliable active optical non-contact measuring device.

\section{Design Principle of the Device}

The device design follows the basic principle of contact measuring methods. High density 2D discrete linear data were measured by laser in order to obtain a surface shape of soil profile (2D linear data). Multiple soil profiles can form the 3D microrelief.

Firstly, two parallel lines were set in the direction of the slope and one projection line of them in the horizontal plane was Y axis. The distance between two lines was the width of soil surface profile (Figure 1). Secondly, contour lines maintained with consistent spacing $(\triangle Y)$ will be set between the two parallel lines, and each contour line corresponds to a soil surface profile line. Then Laser range finder was installed in contour line, and begun to measuring from a zero point. Laser range finder measured the distance between the point of soil surface profile line and the point of contour line (Figure 2). After a point measurement completion, laser range finder was driven by power system (micro-motor) and moved to the next measuring point to do the same measurement until the terminal point, in the measurement process data was recorded and sent. In this way laser range finder completed measurement of a soil surface profile line. And the measuring spacing $(\Delta X)$, or sampling point density, can be adjusted through power system. The data of Laser range finder measured was $2 \mathrm{D}$ discrete data, the moving direction of the laser range finder was $\mathrm{X}$ axis. Through reference plane, the Ln can be converted to the relative elevation $Z$.

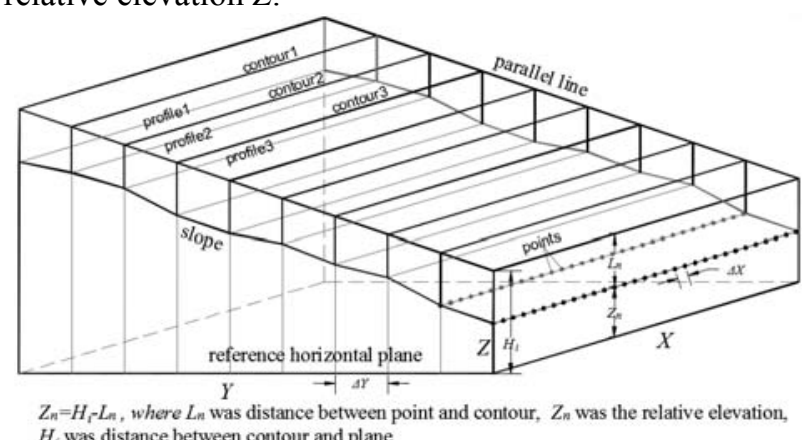
$Z_{n}=H_{i}-L_{n}$, where $L_{n}$ was distance between poi
$H_{i}$ was distance between contour and plane

Figure 1. Sketch of slope measuring. 


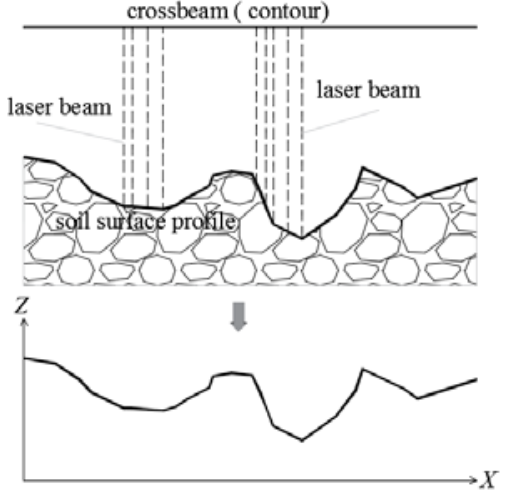

Figure 2. Soil surface profile measuring.

\section{Device Structure}

Soil surface profiler mainly consisted of rail trestle, motor-trolley and data system (Figure 3). The rail trestle included crossbeam and feet, crossbeam for installing the motor-trolley and controlling it going to the designated direction. The feet mainly used for bracing and fixing the crossbeam. The motor-trolley is made up of power system and measuring component, power system included pulley and motor, the measuring component was a laser range finder. Data systems consisted of two parts, bluetooth communication transmission and receiving, transmission part was installed in the laser range finder and receiving part installed in a laptop.

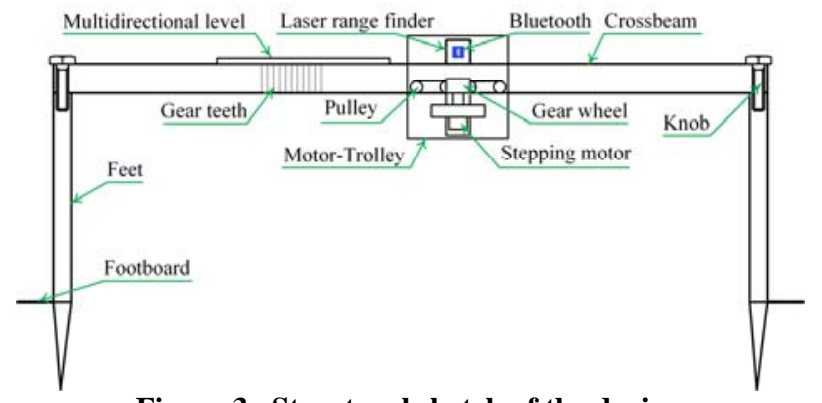

Figure 3. Structural sketch of the device.

\subsection{Rail Trestle}

Crossbeam was the guide path of motor-trolley, as well as the projection parallel line of soil surface profile. The material of crossbeam choose lightweight, high hardness, deformation small aluminium alloy. The crossbeam length $2 \mathrm{~m}$, the actual measuring length of $1.8 \mathrm{~m}$. To ensure the friction of the motor-trolley when walking, vertical gear teeth were processed on the side of the crossbeam, which also called rail. The gear teeth and wheels of the motor-trolley matched in order to control it uniform-velocity walking. Through these gear teeth, the walking speed of the motor-trolley can be control, so as to regulate the density of sampling point. At the same time, considering the horizontal of measuring system on the axial and radial, a multidirectional level was installed in the crossbeam, and adjusting the feet can ensure the level state of crossbeam.

Feet was mainly used to support and balance crossbeam. Due to the feet will Bear a certain weight, and considering portability, so the material selected stainless steel, which $20 \mathrm{~mm}$ in diameter, $2 \mathrm{~mm}$ wall thickness, $1 \mathrm{~m}$ length. The underpart of feet was designed sharp-pointed. At the same time, at the $30 \mathrm{~cm}$ from the bottom, there welded a footboard for the convenience of feet installation. The feet and crossbeam joint with knob.

\subsection{Motor-Trolley}

Motor-trolley included the power part and measuring part. Power part included pulley, slide lock block and stepping motor. Measuring part was a laser range finder. Motortrolley was the core structure of the device (Figure 4).

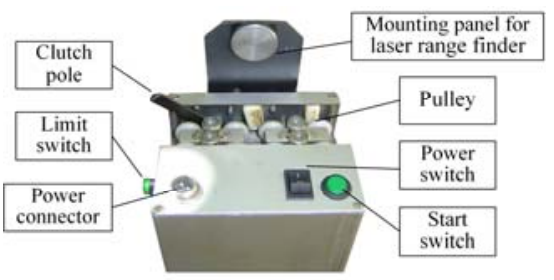

Figure 4. Structure of the motor-trolley.

The pulley of the power part was used to walk for the motor-trolley. Slide lock block was used to locate the motor-trolley. Stepping motor was used to control the walking speed of motor-trolley, i.e. Sampling point spacing or sampling point density, which was the core component in the power part.

According to the accuracy of measuring and the demands of data transmitting and receiving, laser range finder selected the DISTO A6 produced by Leica of Switzerland. The laser range finder attached data receiving software, also had the function of remote control measuring. Main parameters were shown in table1.

Table 1. Main parameters of laser range finder.

\begin{tabular}{|c|c|c|c|c|}
\hline Parameter & $\begin{array}{c}\text { Measuring } \\
\text { range }\end{array}$ & $\begin{array}{c}\text { Measuring } \\
\text { error }\end{array}$ & $\begin{array}{c}\text { Measured } \\
\text { frequency }\end{array}$ & $\begin{array}{c}\text { Data } \\
\text { transmission }\end{array}$ \\
\hline Value & $0.05 \sim 200 \mathrm{~m}$ & $\pm 1.5 \mathrm{~mm}$ & 2.5 times/s & $\begin{array}{c}\text { Bluetooth } \\
\text { TM }\end{array}$ \\
\hline Parameter & Gunsight & $\begin{array}{c}\text { Calculation } \\
\text { function }\end{array}$ & \multicolumn{2}{|c|}{ Waterproofness } \\
\hline Value & $\begin{array}{c}\text { 2times the } \\
\text { telescope }\end{array}$ &,,$+- \times$ & \multicolumn{2}{|c|}{ IP54 } \\
\hline
\end{tabular}

\subsection{Data System}

The DISTO TM software of Bluetooth transmission and receiving function can be installed on a laptop. The laptop with Bluetooth function can automatically search the laser range finder with a Bluetooth transmission function, thus realizing the data transmission and receiving. The receiving data can be imported into Excel, which is convenient for data collation and analysis. At the same time, based on the DISTO TM software, walking speed of motor-trolley can be controlled by programming, i.e. sampling point density control program. And the motor-trolley also can be remotely controlled by the program. 


\section{Circuit System}

The circuit system of the device was composed of two parts, the supply circuit and the walking control circuit. The supply circuit was composed of a lithium battery, a transfer switch, a DC/DC module and a charger. Walking control circuit comprised a working switch, dry reed relays, a limit switch and a micro-motor (Figure.5)

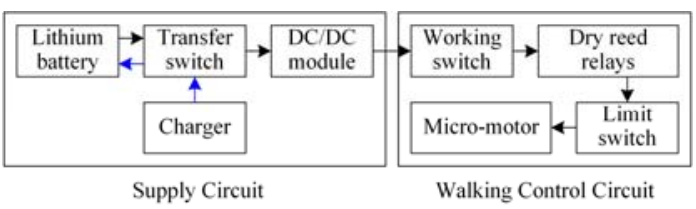

Figure 5. Circuit working principle sketch.

\subsection{Supply Circuit}

Lithium battery was the power source of work. It was required both for a long time to run, but also as light as possible. The large capacity lithium battery technology had matured, already batch production and use, just higher prices, about 2 times of the ordinary battery, but still affordable, and weight was only $2 / 3$ of the ordinary battery. The role of transfer switch was used to change the state between supplying and charging. The DC/DC module was mainly used to output stable working voltage, in order to ensure the motor uniform rotation, so as to keep the measuring distance constant. Voltage and capacity of charger were coincident with that of lithium battery, which were necessary to charge the lithium battery. The main components and parameters of the power supply circuit are shown in Table 2 .

Lithium battery, DC/DC module, micro-motor were integrated into the motor-trolley. When the transfer switch was changed to the power supply state, the electric power of the lithium battery was supplied to the DC/DC module through the transfer switch. Then the DC/DC module regulated voltage to ensure it stability, and stable voltage was supplied to the walking control circuit. When the transfer switch was changed to charging state, the transfer switch cut off the power supply of lithium battery, then the lithium battery accepted charging.

\subsection{Walking Control Circuit}

The working switch connected to the circuit between the power supply circuit and the walking control circuit. The dry reed relay was used to protect circuit, which required small size and low power consumption. The limit switch was used for terminal positioning of the motor-trolley. The micro-motor was the driving force of the motortrolley, required to have a certain torque to overcome the walking resistance, in addition, the walking speed of micro-motor must be uniform and smooth, in order to meet the measurement of laser range finder. The main components and parameters of the walking control circuit are shown in Table 3.
Table 2. Main components and parameters of the power supply circuit.

\begin{tabular}{|c|c|c|}
\hline Component & Parameter & Value \\
\hline \multirow{3}{*}{$\begin{array}{c}\text { Panasonic } \\
\text { Lithium battery }\end{array}$} & Capacity & $5.5 \mathrm{AH}$ \\
\cline { 2 - 3 } Transfer switch & Peak Voltage & DC12.6V \\
\cline { 2 - 3 } & Charging Times & $>500$ times \\
\hline \multirow{5}{*}{ DC/DC module } & Voltage & $\geq \mathrm{DC} 50 \mathrm{~V}$ \\
\cline { 2 - 3 } & Manual Adjustable Voltage & $\geq 3 \mathrm{~A}$ \\
\cline { 2 - 3 } & Input Voltage & DC9.5 40V \\
\cline { 2 - 3 } & Max Output Electric Current & $2 \mathrm{~A}$ \\
\cline { 2 - 3 } & Charging Voltage & DC12. \\
\hline \multirow{4}{*}{ Charger } & Charging Electric Current & $2 \mathrm{~A}$ \\
\cline { 2 - 3 } & Capacity & $5.5 \mathrm{AH}$ \\
\hline
\end{tabular}

Table 3. Main components and parameters of the walking control circuit.

\begin{tabular}{|c|c|c|}
\hline Component & Parameter & Value \\
\hline \multirow{2}{*}{ Working switch } & Voltage & $\geq \mathrm{DC} 30 \mathrm{~V}$ \\
\cline { 2 - 3 } & Electric Current & $\geq 1 \mathrm{~A}$ \\
\hline \multirow{3}{*}{ Dry reed relay } & Coil Voltage & $\mathrm{DC} 12 \mathrm{~V}$ \\
\cline { 2 - 3 } & Coil electric current & $\leq 10 \mathrm{~mA}$ \\
\cline { 2 - 3 } & Contactor electric current & $1 \mathrm{~A}$ \\
\hline \multirow{3}{*}{ Limit switch } & Voltage & $\geq \mathrm{DC} 30 \mathrm{~V}$ \\
\cline { 2 - 3 } & Electric current & $\geq 1 \mathrm{~A}$ \\
\hline \multirow{3}{*}{$\begin{array}{c}\text { DC micro-motor } \\
\text { (ZGX12RP4621) }\end{array}$} & Power & $0.8 \mathrm{~W}$ \\
\cline { 2 - 3 } & Walking Speed & $1 / 15 \mathrm{HZ}$ \\
\cline { 2 - 3 } & Voltage & $\mathrm{DC} 12 \mathrm{~V}$ \\
\hline
\end{tabular}

In power supply state, when the working switch $(A N)$ was pressed. The coil of dry reed relay $(C)$ and the contactor $(c)$ were connected, respectively. Micro-motor $(M)$ began to work. When the working switch released, In the case of the contactor connected, the coil will protect circuit. The micro-motor will continue to work. When the limit switch $(X W)$ pressed, the circuit was cut off, all the circuit restored the starting state (Figure. 6).

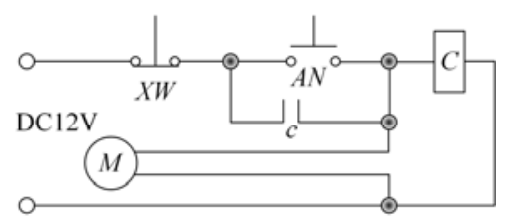

Figure 6. Principle sketch of working control circuit.

\section{Application Example}

Study site located in the Synthetic Science and technology demonstration garden of soil and water conservation in Anji County, China. The sample plot was an eroded bare slope. The experimental time was Aguest 10th, 2015. The area of the sample plot was controlled at 
$180 \mathrm{~cm} \times 251 \mathrm{~cm}$, and sampling density at $\mathrm{X}$ axis and $\mathrm{Y}$ axis direction were set to $1 \mathrm{~cm}$ for a sample point.

Point cloud data obtained from the experiment was taken the filtering processing in order to reject abnormal data. Spatial interpolation and rasterization of the point cloud data were processed through kriging interpolation method of surfer10 software. Then, the spatial microrelief of soil surface was reconstructed through the 3D surface functional module of the software. The result of soil surface microrelief reconstruction was shown in Figure 7. The soil surface microrelief of the model reconstruction was basically consistent with the actual soil surface spatial characteristics.

The development of gully erosion was strong, and two erosion gullies in the middle of the sample plot. The main direction of gully development was along the slope direction ( $\mathrm{Y}$ axis), with max depth more than $50 \mathrm{~cm}$, and width about $40 \mathrm{~cm}$. In the direction of the transverse slope (X axis), the gully erosion also developed, but the depth and width less than that of the main direction.

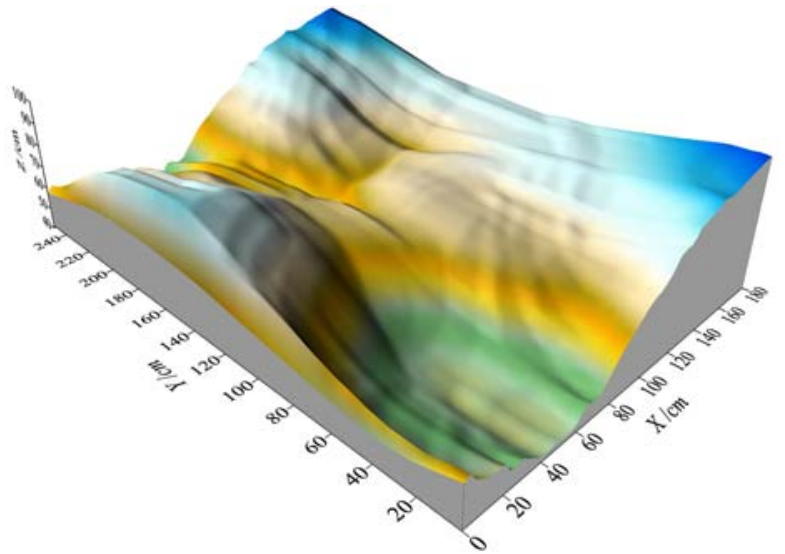

Figure 7. 3D microrelief of soil surface.

\section{Conclusions}

The Project developed a non-contact soil surface profiler based on laser ranging technique and combined with motor control and balance structure. The device can measuring high density 2D sample data of soil surface profile, the $2 \mathrm{D}$ data of many soil surface profiles was integrated to obtained $3 \mathrm{D}$ data of slope, common data analysis software can reconstruct the soil surface microrelief characteristics. Compared with the contact measuring methods, accuracy significant improved, operating time greatly shortened, more data. Compared with the existing non-contact measuring methods, low cost, simple operation, convenient transportation and reliable precision. Howbeit, it was worthwhile to note that when finishing measuring work or changing the measuring profile, the power switch should be turned off in order to extend the use time of the device. Besides, after finishing day's measuring work, the charger should be charged as soon as possible to ensure the next measuring work, and device components should be placed into the backpack in order to avoid damage when transporting.

\section{Acknowledgement}

The author would like to thank the device research and development team for their efforts to the work, they are Xuan Yang, Shuai Wang, Dan Cui, Tao Qiu and Guo-Hui Nie. Also deserving recognition are Ming Shao, for giving important suggestions for improvements in the device. And thank Bing-Run Zhu for his help in field experimental operation. And this work was supported by the Science and Technology Planning Project of Zhejiang Province, China (Grant No. 2015F50060).

\section{References}

[1] H.Kuipers, Neth. J. Agric. Sci.5, 255 (1957).

[2] J.Poesen, J.Nachtergaele, G.Verstraeten, C.Valentin, Catena 50, 91(2003).

[3] R.R.Allmaras, R.E.Burwell,W.E.Larson, Washington: U.S. Department of Agriculture, (1966).

[4] A.Saleh, Journal of Soil and Water Conservation 48, 527(1993).

[5] F.Q.Wu, X.G.Zhao, B.Z.Liu, R.Y.Jia, Journal of Northwest Forestry College 13, 15(1998). In Chinese.

[6] R.E.Burwell, W.E. Larson, Soil Science Society of America Proceedings 33, 449(1969).

[7] G.Hu, Y.Q.Wu, B.Y.liu, Y.Xie, Journal of Soil and Water Conservation 18, 16(2004). In Chinese.

[8] P.R.Robichaud, M.Molnau, Transaction of the ASAE 33, 1851(1990).

[9] M.J.M.Römkens, S.Singarayar, C.J.Gantzer, Soil and Tillage Research 6, 193(1986).

[10]M.Z.Tekeste, R.L.Raper, T.E.Grift, Transaction of the ASAE 47, 23(2004).

[11]J.Zhang, F.L.Zheng, L.L.Wen, F.Y.Yu, J.An, G.F.Li, Bulletin of Soil and Water Conservation 31, 89(2011). In Chinese.

[12] S.K.Nouwakpo, C.H.Huang, Soil Science Society of America Journal 76, 70(2012). 